\title{
THE EYES AND OPTIC PATHS OF THE CATFISH, AMEIURUS
}

\author{
C. JUDSON HERRICK
}

Hull Laboratory of Anatomy, The University of Chicago, Illinois "

SEVENTEEN FIGURES

The relationships and peculiar organization of the siluroid fishes have long been of interest to comparative anatomists. Several systematic descriptions of their general structure have been published and many special reports. Among the latter is Ströer's recent account ('39) of the projection of retinal quadrants upon the optic tectum in representative vertebrates, including among the fishes the siluroids, Ameiurus nebulosus and Clarias.

My own interest in his problem led to restudy of a number of specimens of Ameiurus which were prepared many years ago for other purposes. None of this material is well adapted for investigation of a possible projection of the retina upon the tectum; but in the course of its examination some other features were seen which seem worthy of record. Various physiological studies indicate that the eyes of these fishes have interesting peculiarities and further information about them is desirable.

Ströer says ('39, p. 305) that in Ameiurus retinal fibers from eight separate optic papillae unite into a common trunk of the optic nerve, within which they take parallel courses to the chiasma, where they separate into two bundles derived

\footnotetext{
${ }^{1}$ This work was aided by a grant from the Dr. Wallace C. and Clara A. Abbott Memorial Fund of The University of Chicago. Many friends assisted in various ways and grateful acknowledgments are especially due to Prof. Elizabeth C. Crosby, Director of the Neuroanatomical Laboratory of the University of Michigan, and to Miss Sue Biethan of the Medical Library of that institution.
} 
respectively from the anterior half ( $\mathrm{D}-\mathrm{A}$ bundle) and the posterior half ( $\mathrm{P}-\mathrm{V}$ bundle) of the retina. In the nerve at the chiasma the P-V bundle is dorsal and posterior, the D-A bundle ventral and anterior. These bundles remain distinct in the optic tracts, the P-V bundle medial and the D-A bundle lateral, and they enter the dorsomedial tectal tract and the ventrolateral tract respectively.

The examination of my own material, which includes many specimens of several species of Ameiurus and related genera, leads to general agreement with this account, though with some important differences. Neither Ströer's brief description nor my own study yields convincing evidence of the localized projection of retinal quadrants upon the optic tectum in Ameiurus, though nothing has been seen to justify a denial that such localization may be present.

In 1895 Deyl described the origin of the optic nerve of Ameiurus from ten distinct retinal papillae, from each of which a fascicle of nerve fibers takes a separate course through the retina. Within the scleral canal these unite to form the round trunk of the nerve. It is of interest to learn whether the fascicles from the several papillae are specifically related with retinal quadrants as defined by Ströer-dorsal (D), anterior (A), posterior (P), and ventral (V) - and if so whether these fascicles can be separately followed through the optic nerve to their areas of distribution in the tectum.

\section{YOUNG AMEIURUS}

Through the kindness of Dr. G. W. Bartelmez I have examined several specimens of young Ameiurus melas from a lot measuring from 10 to $18 \mathrm{~mm}$. in length, prepared by a reduced silver method after fixation in alcohol acidulated with acetic acid. The impregnation is excellent in the medulla oblongata, but pale or deficient in the optic system. Two specimens from this lot show details of interest.

One of the smallest of these specimens (no. Am.121) was cut in a longitudinal plane inclined about $45^{\circ}$ to the horizontal, with the (apparent) left side more dorsal. A section 
passing through the ventrolateral border of the left eyeball shows that within the lips of the recently closed chorioid fissure there is a fascicle of optic fibers from the ventral part of the retina. As the sections are read dorsomedially from this level three additional fascicles are encountered, these coming successively from the posterior, anterior and dorsal parts of the retina. These four fascicles are quite distinct from one another. They leave the retina by widely separated optic papillae, take separate courses through the retinal layers, and unite in the chorioid to form the trunk of the optic nerve. Here they are unimpregnated and cannot be separately followed to the brain. At this early stage the separate optic papillae and related fascicles seem to be specifically related with the retinal quadrants. But examination of the larger specimens of this lot of fry and of the adults in my own collection shows that these do not conform with this simple pattern.

A larger specimen of this lot, $18 \mathrm{~mm}$. in length (Bartelmez' no. Am.100), was sectioned transversely. Nerve fibers are lightly but clearly impregnated in all parts of the retina. These unite to form fascicles which converge to eight papillae in the right eye and to nine papillae in the left eye. Some of these fascicles are large and some very small with very few impregnated fibers. The fibers of the larger fascicles can be followed from their papillae out to the marginal zone of the retina. Some of the papillae are entered by a single well defined fascicle, in others several fascicles converge from different directions. Some of the papillae are widely separated from the others; some are grouped, two or three very close together.

The eight papillae of the right eye are distributed in a zone which extends from near the center of the retina ventrally and forward to its ventral margin near the ora serrata. If, as suggested beyond, this zone marks the approximate locus of the closed chorioid fissure, then its topographical relations in the eyeball are changed between the closure of the fissure, this stage of development and the adult. The arrangement and 
composition of these eight papillae and the related fascicles of fibers are intermediate between those seen in the four papillae of the younger specimen described above and the adult to be described and illustrated shortly. The retinal connections of each papilla are clearly seen and it is evident that the fibers which converge to the several papillae are not in all cases derived from single quadrants. In some of the smaller papillae this seems to be true, but not in the larger. There is some appearance of segregation of D-A groups from P-V groups, but the evidence for this is not clear.

In the left retina there are nine papillae arranged in principle about as in the right eye, though the details of location and composition are different.

The fascicles of nerve fibers derived from the several retinal papillae retain their identity for considerable distances in the optic nerve. They cannot in this specimen be separately followed through the nerve to the brain and it certainly would be difficult to do this even if there were available an abundance of suitably prepared material cut in favorable planes; for throughout the length of the optic nerve there is continuous anastomosing and interweaving of small fascicles in very complicated arrangement. At the chiasma the two optic nerves cross, the (apparent) right dorsally of the left. There is no clear separation here of the fibers of each nerve into dorsal (P-V) and ventral (D-A) bundles, such as illustrated by Ströer ('39, figs. 1 to 3) in Salmo salar of comparable stage.

A lot of Ameiurus nebulosus about $20 \mathrm{~mm}$. long prepared in 1891 and stained with Delafield's haematoxylin includes two specimens cut sagittally. The stain is now much faded, but both specimens show throughout the length of the optic nerves a more or less evident separation of the fibers into dorsomedial and ventrolateral bundles. Neither the retinal nor the cerebral connections of these bundles are demonstrable. These two are the only specimens of our collection, young or adult, which yield any evidence of a separation of the fibers of the optic nerve between eyeball and chiasma into the D-A 
and P-V groups as defined by Ströer, and here only the coarsest fibers of the nerves are visible. In all of the other specimens the nerve is composed of many small fasciculi which anastomose in complicated patterns. This negative evidence does not justify the inference that retinal quadrants are not projected upon the tectum, but except for these two poorly preserved specimens none of our material shows any separation of retinal fascicles in the peripheral nerve. At the chiasma there is an evident rearrangement, with separation of fibers of the dorsal and ventral tectal tracts.

\section{ADULT OPTIC NERVES AND TRACTS}

Our collection includes the heads of three specimens of adult $\mathrm{A}$. melas which were fixed and decalcified in Flemming's stronger fluid, frequently renewed for 2 or 3 weeks, embedded in paraffin, cut transversely and stained by Weigert's method. The fixation and stain are excellent but the friable tissue requires skillful handling. In two of these, part of one side of the head, including the eye, was cut away before fixation. These sections were so broken in preparation as to be useful only as controls. The third specimen (no. 1177) includes the entire head and the transverse sections of $13.3 \mu$ are in good order and well stained. My account of the nerves and cutaneous sense organs published in 1901 was based chiefly upon this specimen, an adult of moderate size, the transverse diameter of the head at the posterior borders of the eyes being $10 \mathrm{~mm}$. measured on the slide.

The North American species studied by Deyl (1895) was ascribed to Amiurus catus, and this is probably Ameiurus nebulosus of the now current nomenclature. Similar conditions were found in Silurus glanis and Cobitis fossilis. He describes in A. catus eight or ten retinal papillae arranged in pairs on opposite sides of an axis marked by the course of a large blood vessel which he terms a. hyaloidea. This is the vitreous artery of my following description (fig. 15). This axis is regarded as the site of closure of the embryonic chorioid fissure and of the retinal and vitreous cleft which persists in 
the adults of many other species of fishes, including Cobitis, though it is not evident in the siluroids. In A. catus the arrangement of the retinal papillae and of the vitreous artery with its larger branches may be seen on ophthalmoscopic examination. More recently Marie-Louise Verrier ('28, p. 71, fig. 26, p. 117) illustrates a section through the eyeball of Ameiurus nebulosus and says that she finds only five retinal papillae.

In my study published in 1901 the multiple retinal papillae were seen and the intraocular fasciculation is crudely indicated on the projection shown as figure 1 of that paper. This figure is used as the basis for figure 1 of the present account, showing in projection on a horizontal plane the eye, optic nerve, and anterior part of the brain of the apparent right (actual left) side. The vitreous artery enters the vitreous chamber from the ventral side at the ora serrata at the point marked, $x$, and the broken line extending from this point medially marks the course of this vessel through the vitreous chamber and the probable line of closure of the embryonic chorioid fissure (fig. 15).

These observations on A. melas confirm, in the main, Deyl's description of $\mathrm{A}$. catus; the minor disagreements are in part specific differences and in part perhaps due to different treatment of the material. In both species the retinal papillae are arranged in a meridional zone whose axis is marked by the vitreous artery. This zone, without doubt, also marks the field derived from the lips of the closed chorioid fissure. In A. catus the papillae are in pairs symmetrically placed on opposite sides of the axis. In my projection of A. melas they are arranged less regularly along the axis. This difference may be an artifact due in part to their convergence in projection and in part to irregularities in the sections. It is impossible for me to correlate the relations of vitreous artery and retinal papillae of A. catus shown in Deyl's ophthalmoscopic view (his fig. 1 ) with my observations of $\mathrm{A}$. melas if I understand correctly his brief description. (On the precautions to be observed in the interpretation of ophthalmo- 
scopic views of the eyes of fishes see Virchow, $1882 \mathrm{a}$, p. 49.) I shall, accordingly, describe these in some detail.

The optic nerve fibers take the Weigert stain brilliantly from the retina to the tectum. For most of their courses within the nerve-fiber layer of the retina they are unstained, but as they assemble into fascicles which converge toward their respective papillae they are faintly stained so that the sources of the larger fascicles can be determined. This stain is intensified to deep blue as they pass from the papilla through the retina into the optic nerve. Since the zone containing the papillae and the vitreous artery marks the place of closure of the embryonic chorioid fissure, its position corresponds also with that of the plica ventralis as pictured in Triton by Ströer ('39, fig. 16), thus separating the ventral retinal quadrant below and posteriorly from the anterior quadrant above and anteriorly. The other boundaries of these quadrants and of the dorsal and posterior quadrants are not recognizable.

The appearance and arrangement of some of the papillae as seen in the transverse sections are illustrated in figures 2 to 4. Some are very small, others are moderately large. From each papilla a separate fascicle of fibers passes through the

\section{ABBREVIATIONS}

a.gen., area geniculata

a.ir., iridian artery

a.vit., vitreous artery

b.ol., bulbus olfactorius

b.v., blood vessel

cb., cerebellum

ch., chiasma optieum

com.ant., commissura anterior

com.hor., commissura horizontalis

com.ig., commissura intergeniculata.

com.tr., commissura transversa.

com.tub., commissura tuberis

ep., epiphysis

f.op.m., fasciculus opticus medialis

hab., habenula

hem., cerebral hemisphere

\author{
hyp., hypophysis \\ n.op., optic nerve \\ nuc.po., nucleus preopticus \\ nuc.po.m., nucleus preopticus magno- \\ cellularis \\ pl.ret., retinal eapillary plexus \\ psbr., pseudobraneh \\ st.gan., retinal ganglion cells \\ str.med., stria medullaris \\ tr.hyp., tractus hypophyseus \\ tr.ol.hy., tractus olfacto-hypothalanieus \\ tr.po., tractus preopticus \\ tr.taen., tractus taeniae \\ v.cir., circular vein \\ v.vit., vitreous vein
}



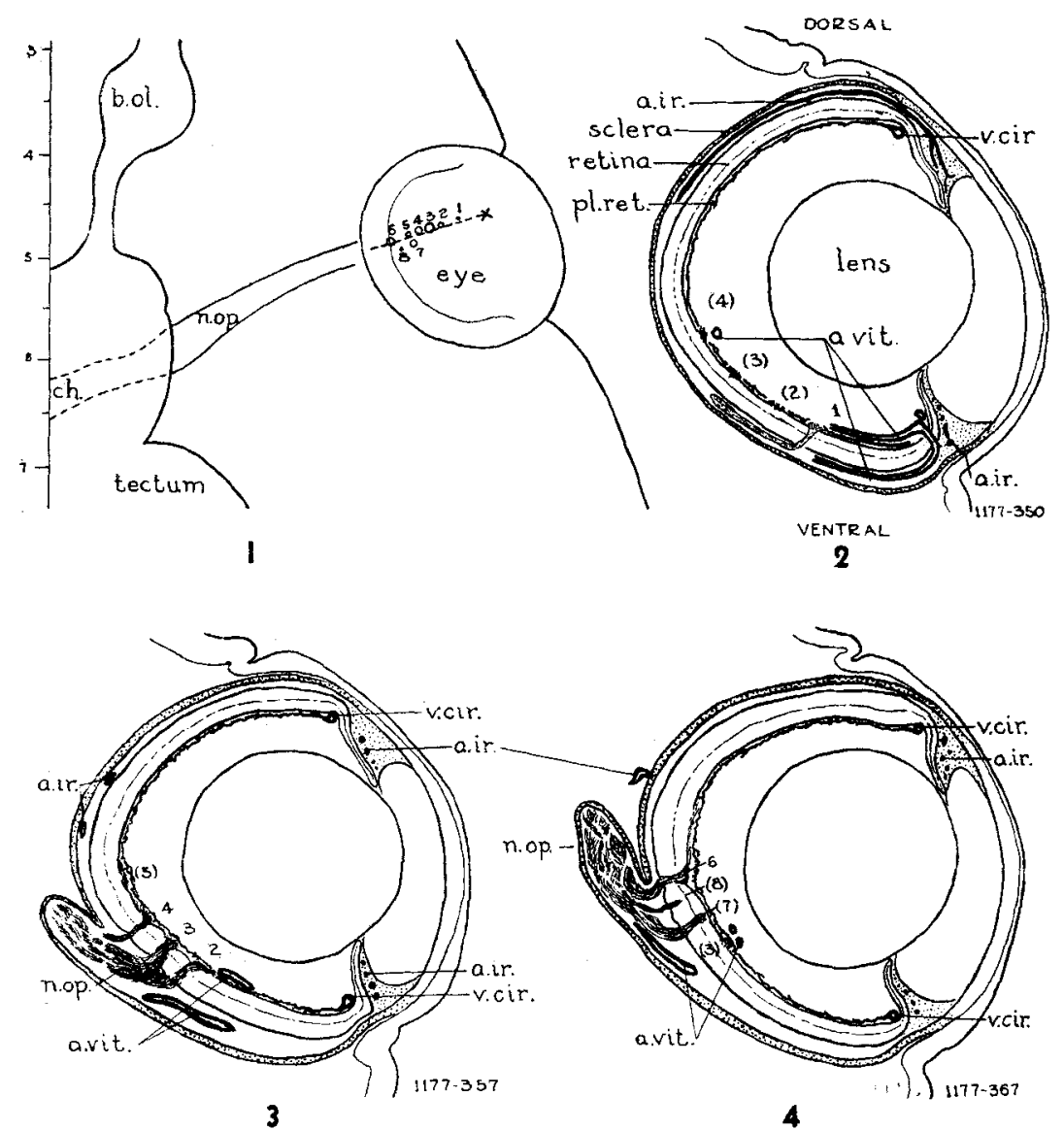

Fig. 1 A projection upon the horizontal plane of the apparent right (actual left) eye and optic nerve of adult Ameiurus melas, illustrating the arrangement of the eight optic papillae. These are projected from transverse sections upon a plane passing through the middle of the eyeball. The outline was traced from figure 1 of $\mathrm{my}$ paper of 1901, reduced to smaller scale $(X 11)$, and reversed from left to right to facilitate comparison with figures 2 to 4 which are drawn from these sections as they appear reversed under the microscope. The scale at the left marks the midplane and distances in millimeters from the rostral tip of the head. The point of entrance into the retina of the vitreous artery is indicated $(x)$ and the broken line extending from this point obliquely to the medial border of the eyeball marks the probable locus of closure of the embryonic chorioid fissure.

Figs. 2 to 4 Three transverse sections through the right eyeball of adult Ameiurus melas, Weigert method. $\times 24$. The drawings are semidiagrammatic, illustrating the arrangement of the retinal papillae and arterial blood supply. The sections being $13 \mu$ thick, the intervals between the figures can be computed from the section numbers given. Papillae are numbered in anterior-posterior sequence from 1 to 8 , numbers in parentheses indicating fascicles of retinal nerve fibers whose papillae of corresponding number lie anteriorly or posteriorly of the plane illustrated. 
retina and in the chorioid these unite to form the trunk of the optic nerve. As this trunk leaves the eyeball the sclera is extended around it as a fibrous sheath (figs. 3, 4, 15). Farther proximally this sheath is divided into a dense inner layer and a looser outer layer with the four ocular blood vessels between them. The extracranial course of the nerve is much longer than the intracranial course, for the skull closely invests the brain. For the topography in the region of the optic foramen see figure 3 of the paper of 1901, which was drawn from section 445 of this series.

In figures 2 to 4 the papillae are numbered anteroposteriorly from 1 to 8 . The numbers enclosed in parentheses refer to fascicles of fibers which enter the papillae of corresponding number out of the plane of the section illustrated. Papilla no. 1 is the most anterior and lateral. It is small and all of its fibers come from the ventral part of the retina anteriorly of this locus, presumably therefore from the anterior quadrant. Papilla 2 is larger, receiving fibers from the ventral part of the retina both anteriorly and posteriorly, i.e., from anterior and ventral quadrants. Number 3 is the largest papilla, receiving fibers certainly from anterior and ventral quadrants and perhaps also from dorsal and posterior. Number 4 is of medium size. Its fibers come from the anterior quadrant and perhaps also from the dorsal. No fibers enter it from levels more posteriorly. Number 5 is small, receiving fibers from the central and perhaps dorsal parts of the retina anteriorly of this level, none entering it from the posterior levels. Number 6 is large and is the farthest medial, near the center of the retina. All of its fibers enter from the dorsal side, most of them evidently coming from the dorsal quadrant. Number 7 is also large. All of its fibers enter from the posterior side, presumably chiefly from the posterior quadrant. Number 8 is very small, receiving fibers from an area in the middle part of the retina which is probably the anterodorsal part of the ventral quadrant.

When this arrangement is compared with that of the left eye and with that of the $18-\mathrm{mm}$. specimen previously de- 
scribed, there is general similarity of pattern but wide variation in the details of both arrangement and composition of the papillae. Some papillae apparently receive all of their fibers from a single quadrant; others evidently do not; and the wide range of variation indicates that there is no constant specific correlation between papillae and quadrants.

The fascicles derived from the several papillae retain their identities for variable distances within the trunk of the optic nerve, but sooner or later all are merged in a bewildering complexity of interlacing small bundles. In the optic nerve the fibers are arranged in from thirty to fifty fasciculi of various sizes which anastomose in constantly changing patterns. As the optic nerve approaches its foramen there is radical rearrangement of all fascicles and intricate interweaving of fibers, with the result that in the short intracranial course of the nerve and in the chiasma the fibers of each nerve are more or less clearly separated into dorsal and ventral bundles of about equal size. These correspond in topographic relations respectively with the $\mathrm{P}-\mathrm{V}$ and $\mathrm{D}-\mathrm{A}$ bundles of Ströer, but whether they have this composition cannot be determined in this material.

In the optic chiasma of most species of teleosts the nerves cross as separate bundles dimorphically, i.e., with the right nerve dorsal in about half of the individuals and ventral in half (Parker, '03). In Clupea, as has long been known, one nerve perforates the other and in some species the two nerves interdigitate in complicated patterns (see the summary by Meader, '34, p. 370). Ameiurus is typically dimorphic, in Parker's sense, but in one of our adult specimens (no. 682) in which the (apparent) right nerve crosses ventrally of the left a well defined fascicle of fibers separates from the dorsal surface of the right nerve to cross dorsally of the left nerve, as shown in figure 15. The right nerve is thus perforated by the left. This seems to be an individual variation, for it is not present in several other adults examined.

In A. melas, a small species with broad and short head, the eyeball is not far anterior to the transverse plane of the 
chiasma and the optic nerve passes across the head nearly transversely (fig. 1). In the larger North American siluroids the eyes are much farther forward with reference to the chiasma. For instance, in specimens of the yellow catfish, or mud catfish (Pilodictis olivaris Gill and Jordan), weighing from 2 to $10 \mathrm{~kg}$., my dissections (1891, figs. 4, 5) showed the optic nerves lying parallel and close to the midplane for a long distance before reaching the chiasma under the anterior ends of the cerebral hemispheres. In A. nebulosus the nerves take a similar though shorter course (figs. 12,13). The central connections of the optic fibers of A. melas resemble those of A. nebulosus to be described immediately, though with minor differences in the relative sizes and arrangements of the component fascicles.

In my examination of the feeding habits of catfish (' 03 , p. 253) it was reported that the channel catfish, Ictalurus punctatus Jordan, is a better visualizer than Ameiurus nebulosus. The eyes are larger with more perfectly differentiated retinal elements (Eigenmann) and these fishes occasionally are caught with a spoon hook. The optic nerves and tracts are notably larger than in Ameiurus, as is evident by comparison of the transections shown in figures 9 and 10 with my brother's figures of Ictalurus (C. L. Herrick, 1892, plate XII, figs. 1 to 4 ). These differences are confirmed by examination of the sections of Ictalurus from which my brother's figures were drawn (specimen no. 48). The transections shown in figures 6 to 8 of my paper of 1891 are erroneously ascribed to Ictalurus. They were drawn from no. 87, A. nebulosus. Comparative study of these two species may yield additional data about the composition of the optic tracts.

The brains of three specimens of adult A. nebulosus about $20 \mathrm{~cm}$. long were embedded in celloidin, cut in transverse, horizontal and sagittal planes, and stained by the method of Weigert-Pal, with excellent results. The stumps of the optic nerves were cut very long so as to include their entire intracranial parts. In this part of the nerve the fibers are well preserved and stained. No counts have been made, but at a 
rough estimate the total number is of the order of 10,000 . Bruesch and Arey ('40) report that the average number of fibers in the optic nerve of the "bullhead" (species not stated) is 26,626 , all of which are myelinated.

In the vicinity of the foramen this nerve is nearly round in cross section and is composed of about 100 small fascicles which are compactly arranged and take approximately parallel courses. There is no evidence of folding and the intrinsic connective tissue is scanty. Each of these fascicles contains fine and medium myelinated fibers and a smaller number of very large fibers. The latter are distributed fairly uniformly in all fascicles. There is no evidence that retinal fascicles have retained their identity here and there is no obvious separation of fascicles into D-A and P-V bundles.

As the chiasma is approached, there is radical rearrangement of the fascicles, with much anastomosis. Sections which cut the nerve lengthwise show small compact fascicles passing from side to side in various directions, all intricately interwoven. This arrangement continues throughout the region of decussation, which is outside the brain under the cerebral hemispheres (figs. 5, 6). In this region there is an evident shifting of many of the coarsest fibers toward the dorsal or dorsolateral side of each nerve and small fascicles of finer fibers pass from all parts of the nerve toward its ventromedial side. At the decussation these relations are reversed, the lateral fascicles of the nerve becoming medial in the optic tract and the medial fascicles becoming lateral. A transverse section through the middle of the chiasma (fig. 6) shows the (apparent) right nerve crossing dorsally of the left toward the left optic tract. The dorsal and medial parts of the crossed nerves contain a larger proportion of very thick fibers than do their lateral parts, though both coarse and fine fibers are present in all fascicles. At this level the dorsal nerve is cut obliquely and slender fascicles of finer fibers are directed laterally. In the brain these enter the lateral part of the optic tract and the fascicles containing more of the coarsest fibers enter the medial fascicles of the tract. 

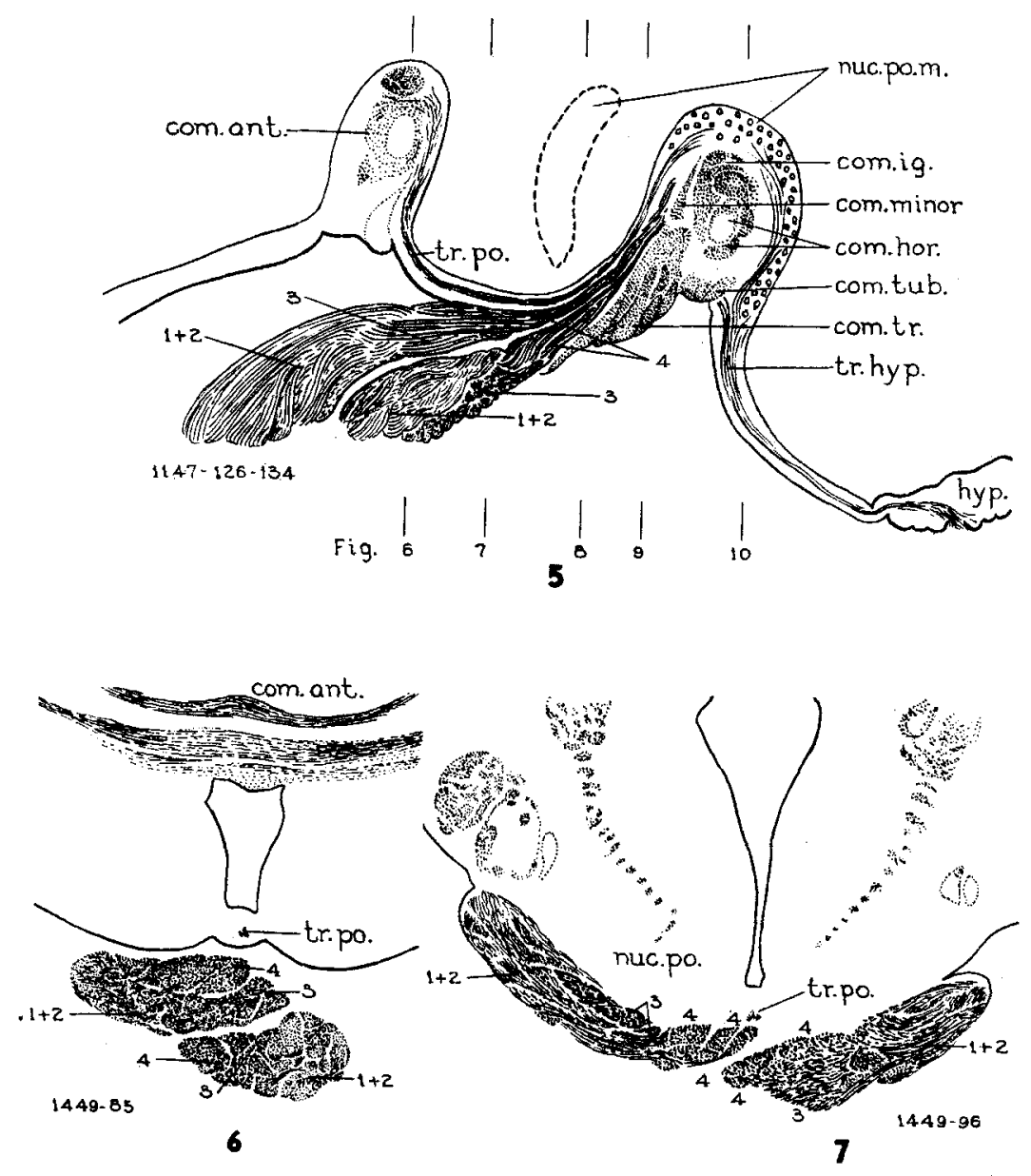

Fig. 5 Semidiagrammatic median section of the chiasma region of adult Ameiurus nebulosus. $\times 24$. Drawn by projecting on the median plane parts of eight slightly oblique sagittal sections prepared by the method of Weigert-Pal. The area outlined by a broken line between the anterior commissure and the chiasma ridge marks the position close to the midplane of the pars magnocellularis of the preoptic nueleus, as shown in transection in figure 8 . The indicated planes of section of figures 6 to 10 are only approximate, for the proportions of the two specimens differ.

Figs. 6 to 10 Transverse sections of adult A. nebulosus, illustrating the courses of optic fibers from the chiasma to the optic tectum, method of Weigert-Pal. $\times 24$. The right side is slightly more rostral.

Fig. 6 Through the ehiasma at the level of the anterior commissure.

Fig. 7 At the entrance of the optic tracts into the brain. 
In my eurrent study of the optic nerves of Amblystoma ('41) and Necturus ('41 a) I found that at their crossing' in the chiasma these fibers are grouped in four ill-defined bundles which were numbered 1 to 4 in ventrodorsal sequence. These correspond topographically with the A, D, V, P bundles respectively of Ströer's description of Triturus, but I was unable to demonstrate the continuity of these chaismatic bundles with either retinal quadrants or tectal tracts. A similar arrangement is found in Ameiurus. At the chiasma there is a very incomplete segregation of the fibers of each nerve into bundles which in the sections here illustrated are numbered 1 to 4 . Peripherally there is no demonstrable continuity of these chiasmatic bundles with fascicles from the retinal quadrants. Their central courses are more in accord with Ströer's schema, where $1+2$ (D-A) fibers enter the ventral tectal tract and $3+4(\mathrm{P}-\mathrm{V})$ fibers enter the dorsal tract. The more ventromedial fascicles of the peripheral nerve take a lateral position in the thalamic part of the optic tract and enter the ventral tectal tract and the more dorsolateral fascicles of the nerves are medial in the thalamus and dorsal in the tectum. But this segregation of the bundles is not very evident, for the limits of the groups of fascicles are not everywhere clearly defined and there is some anastomosis and rearrangement of these fascicles both before and after their entrance into the brain. It is certain that in all our specimens of adult Ameiurus there is no demonstrable continuity of the $1+2$ ("D-A") and $3+4$ ("P-V") bundles with fascicles from the retinal quadrants and that the fibers so designated in figures 5, 6 and 11 do not all enter the ventral and dorsal tectal tracts respectively. Yet it is clear that some, probably a majority, of the fibers of these chiasmatic bundles do take courses to the tectum similar to those so designated by Ströer.

The configuration of the chiasma region as seen in midsagittal section is shown in figure 5. The optic decussation is outside the brain ventrally of the anterior commissure, which occupies a high ridge in the ventricular floor. Posteriorly 

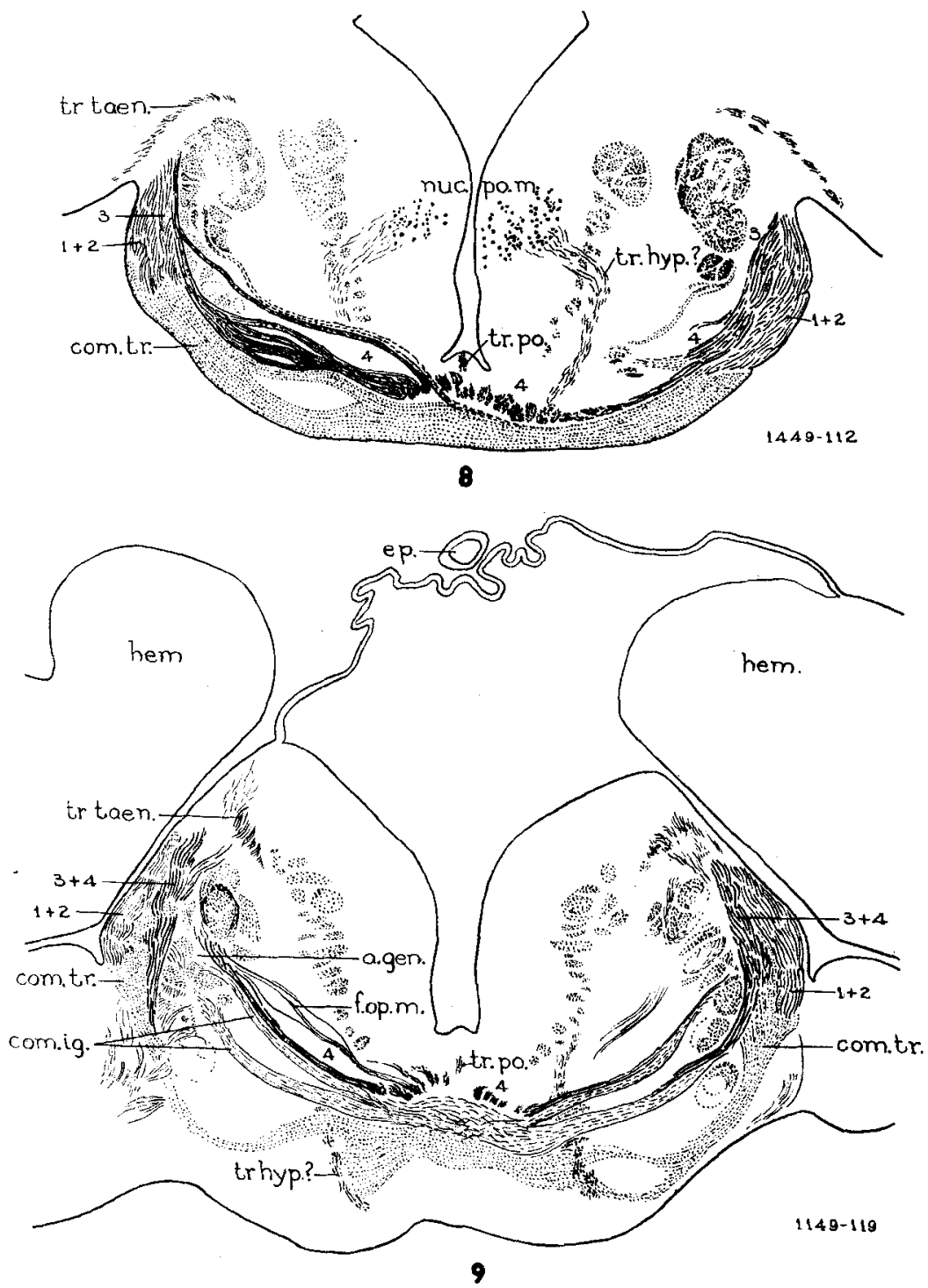

Fig. 8 Midway between the anterior and postoptic commissures. Optic fibers of the $1+2$ group are lateral in the marginal tract, those of group 3 are medial. Faseicles of group 4 are median and the aberrant fascicles are passing laterally to rejoin bundle 3 in the marginal tract. The left side is sehematized by projection on the plane of this section of the aberrant optic fascicles from several neighboring sections. All of these are accompanied by fibers of the commissura transversa, though these are not drawn in the middle three fascicles.

Fig.9 Through the anterior part of the geniculate area, which receives faseicles of the intergeniculate commissure, accompanied by optic fibers of group 4, and also terminals of the faseiculus opticus medialis. On the left side the separate strands of the latter system are projected from several sections. These slender strands are accompanied by fibers of the commissura minor which are not drawn. 
of this ridge the floor of the preoptic recess is thin and nonnervous except for fibers of the tractus preopticus. Posteriorly of this recess is a massive eminence containing the postoptic commissures which in conformity with the amphibian arrangement is here termed the chiasma ridge, though in Ameiurus no optic fibers decussate here. The characteristic cells of nucleus preopticus magnocellularis form a compact group in the middle of the preoptic area of each side (figs. 5, $8,12,13)$ and cells of similar appearance in the Weigert sections occupy the posterodorsal border of the chiasma ridge. Fibers of tractus hypophyseus seem to arise from both of these nuclei. Detailed analysis of the postoptic commissure complex has not been attempted, though its major components are evident. There is no confusion between commissural fibers and optic fibers because they stain differently in the Weigert sections.

The ventral region of the brain between the anterior commissure and the chiasma ridge is very vascular. Some of the larger meningeal vessels are drawn in figure 13, dorsally of this region, to illustrate the chief source of the intrinsic blood vessels of the optic nerves, which enter from their dorsal sides in the chiasma region. A plexus of small vessels ramifies throughout the length of the optic nerves, but as pointed out beyond, these do not form a central retinal artery.

At the level of entrance of the optic fibers into the brain (fig. 7) the segregation of the medial relatively coarse-fibered bundles from the lateral fascicles of finer fibers is more evident, though there is no clearly marked boundary between them and fibers pass freely from one group to the other.

Immediately upon entrance into the brain the most medial optic fascicles of group 4, which here contain most of the thickest fibers of the nerves, turn rather sharply dorsally and form a row of small round bundles immediately under the ependyma of the preoptic recess, which is here dilated laterally (figs. 5, 8, 11). These bundles of group 4 ascend in and near the midplane across the rostral face of the chiasma ridge. The optic fibers of groups 1,2 and 3 continue their 
course directed laterally to form the marginal optic tract. Fibers of the commissura transversa appear at the anteroventral border of the chiasma ridge and the medial optic bundles of group 4 ascend across its anterior face (figs. 5, 8).

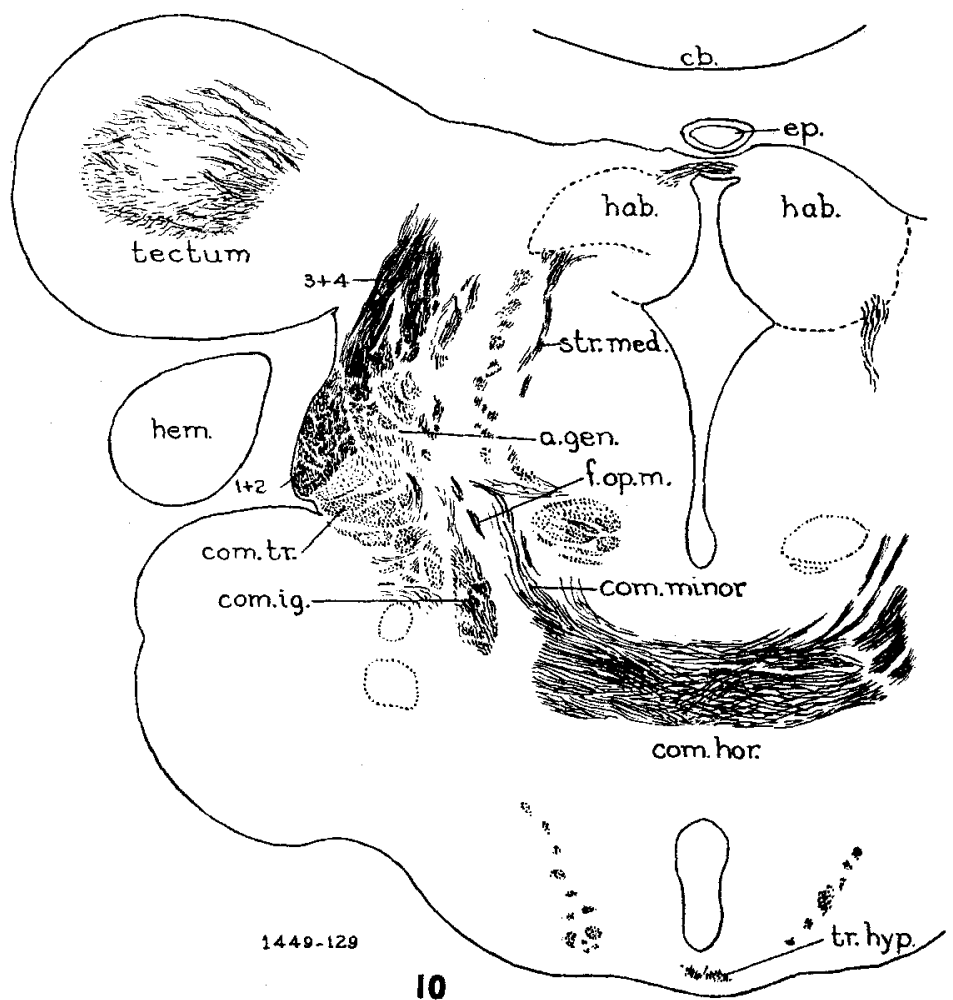

Fig. 10 This section cuts the crossing of the horizontal and habenular commissures, the posterior end of the cerebral hemisphere and the anterior end of the optic lobe, passing through the middle of the genieulate area, where dorsal and ventral tectal tracts are separating.

At the level of figures 8 and 12 the marginal optic tract is ascending on the lateral aspect of the preoptic nucleus with fibers of group 3 internal and those of groups 1 and 2 external. These fibers are widely separated from the more medial fascicles of group 4. The more lightly stained fibers of the transverse commissure are crossing ventrally and posteriorly 
of those of group 4 and from here they spread laterally across the ventral aspect of the brain as far as the marginal optic tracts. Some of the commissural fibers separate from the others, passing laterally at deeper, i.e., more dorsal, levels in several flattened fascicles. Accompanying these are the most lateral fascicles of group 4 which turn sharply outward to join those of group 3 on the inner side of the marginal tract, as shown in figure 8 . Further comment on these aberrant optic fascicles is made beyond. The remaining fibers of group 4 continue caudad for a short distance near the midplane and then turn dorsolaterally in small fascicles which are accompanied by similar fascicles of the commissura minor (figs. 9, 10, 13). These more posterior fibers of group 4 comprise the thalamic fasciculus medialis of the literature.

In Ameiurus the large corpus cerebelli is inclined forward over the midbrain and the valvula cerebelli is thrust forward into the mesencephalic ventricle. The pressure of these cerebellar masses crowds the optic lobes forward, downward and laterally, somewhat as in birds, resulting in atypical topographic relations. Internally this brain exhibits many other peculiarities, among which are the aberrant optic fibers of group 4 and the absence of a well defined corpus geniculatum laterale (Franz, '12, p. 410).

At the level of the rostral ends of the optic lobes the thalamic marginal optic tracts separate into dorsal (medial) and ventral (lateral) tectal tracts (figs. 10, 14). The dorsal tract takes the larger part of the chiasmatic bundles 3 and 4 and the ventral tract most of bundles 1 and 2 . These bundles are in some places so obscurely separated that exact determination of the composition of the tectal tracts is impossible. From the point where the aberrant fascicles of group 4 rejoin the marginal optic tract (fig. 8) most of their fibers clearly ascend to the anterodorsal part of the tectum in company with those of bundle 3 ; but some of them appear to enter the ventral tectal tract in company with bundles 1 and 2 and others spread out and apparently end in the neuropil of the geniculate area. 
The term area geniculata is applied to a field with indefinite boundaries lying internally of the optic tracts in the region of their separation into dorsal and ventral tectal tracts. This region, which contains cells, neuropil, and many small fascicles of fibers of various connections, probably includes an undifferentiated lateral geniculate nucleus and some other structures. Here many optic fibers of group 4 evidently terminate and perhaps some from other bundles. These in the aggregate are comparable with the fasciculus geniculatus observed in Holocentrus by Meader ('34, p. 377). The most medial fascicles of group 4, comprising the fasciculus medialis, spread out and apparently terminate in the area geniculata (fig. 9). They are accompanied by fibers of the commissura minor (C. L. Herrick, 1892, p. 37) and commissura intergeniculata (Meader, '34, p. 393), as seen in figure 13.

The recent description of the dieneephalon of Corydora paliatus by Ruth N. Miller ('40) is devoted primarily to the cellular pattern. The brief account of the optic nerves and associated commissural tracts shows that in this siluroid fish their arrangement is different from that of our North American species. She illustrates well defined dorsal and ventral divisions of the lateral geniculate nucleus; our material is inadequate to show whether a similar differentiation is present in Ameiurus.

Figure 5 shows that the greater part of the chiasma ridge is occupied by the large postoptic commissure systems. The available material is insufficient for an adequate analysis of this complex. The commissura transversa includes a large connection with the torus semicircularis and smaller connections with the tectum and area geniculata which pass below and through the gray of the preoptic nucleus in many fascicles. Its most ventral fibers cross as a massive bundle at the lower surface (figs. 5, 8) and ascend ventrally and posteriorly of the marginal optic tracts and in part mingled with these. Most of these fibers connect with the torus semicircularis, but some of them enter the tectum in company with optic fibers. Other fibers at more dorsal levels accompany the aberrant optic 

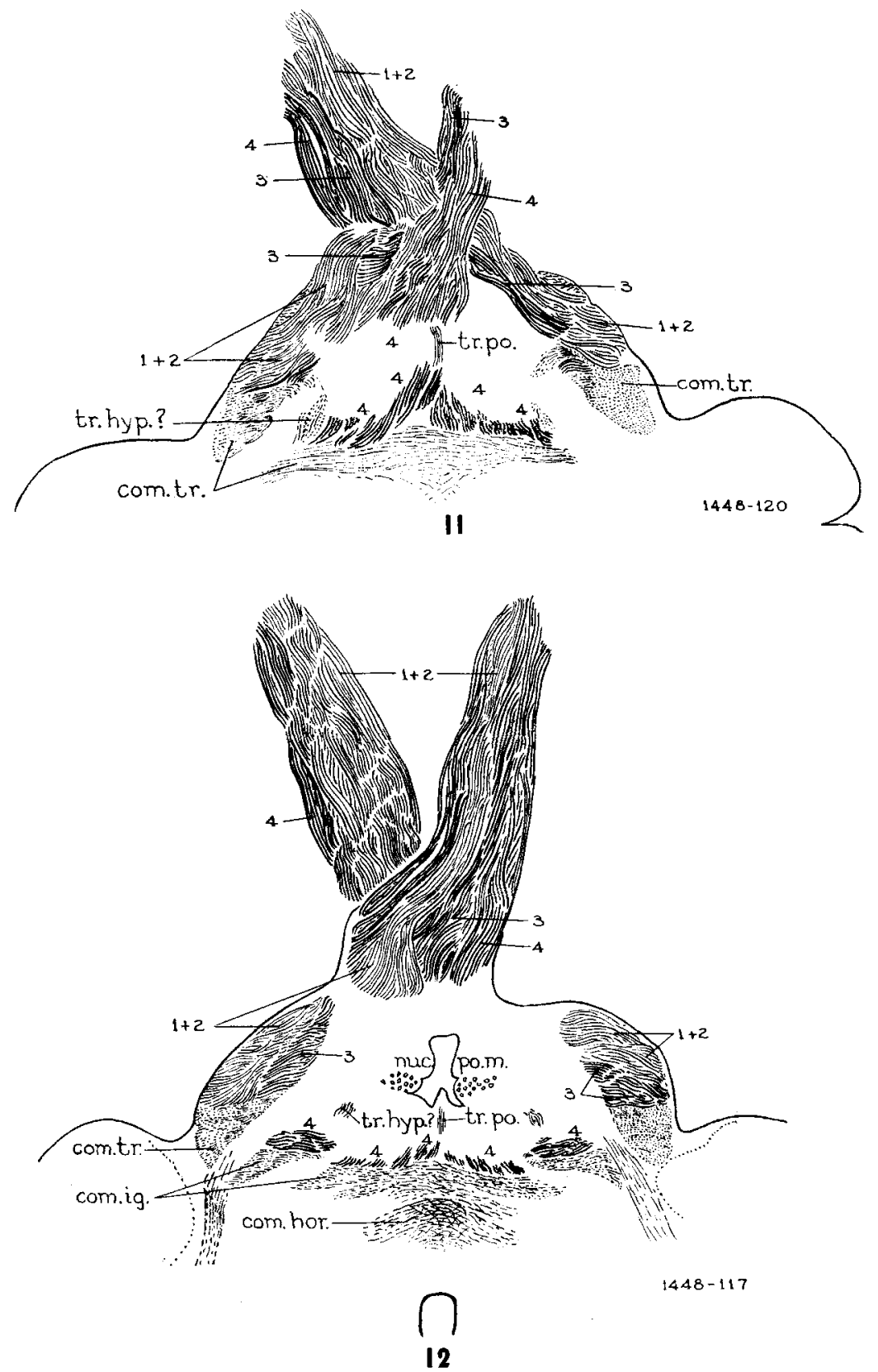

Figs. 11 to 14 Horizontal sections of adult $A$. nebulosus, showing the optic pathways from the chiasma to the tectum, method of Weigert-Pal. $\times 24$. 

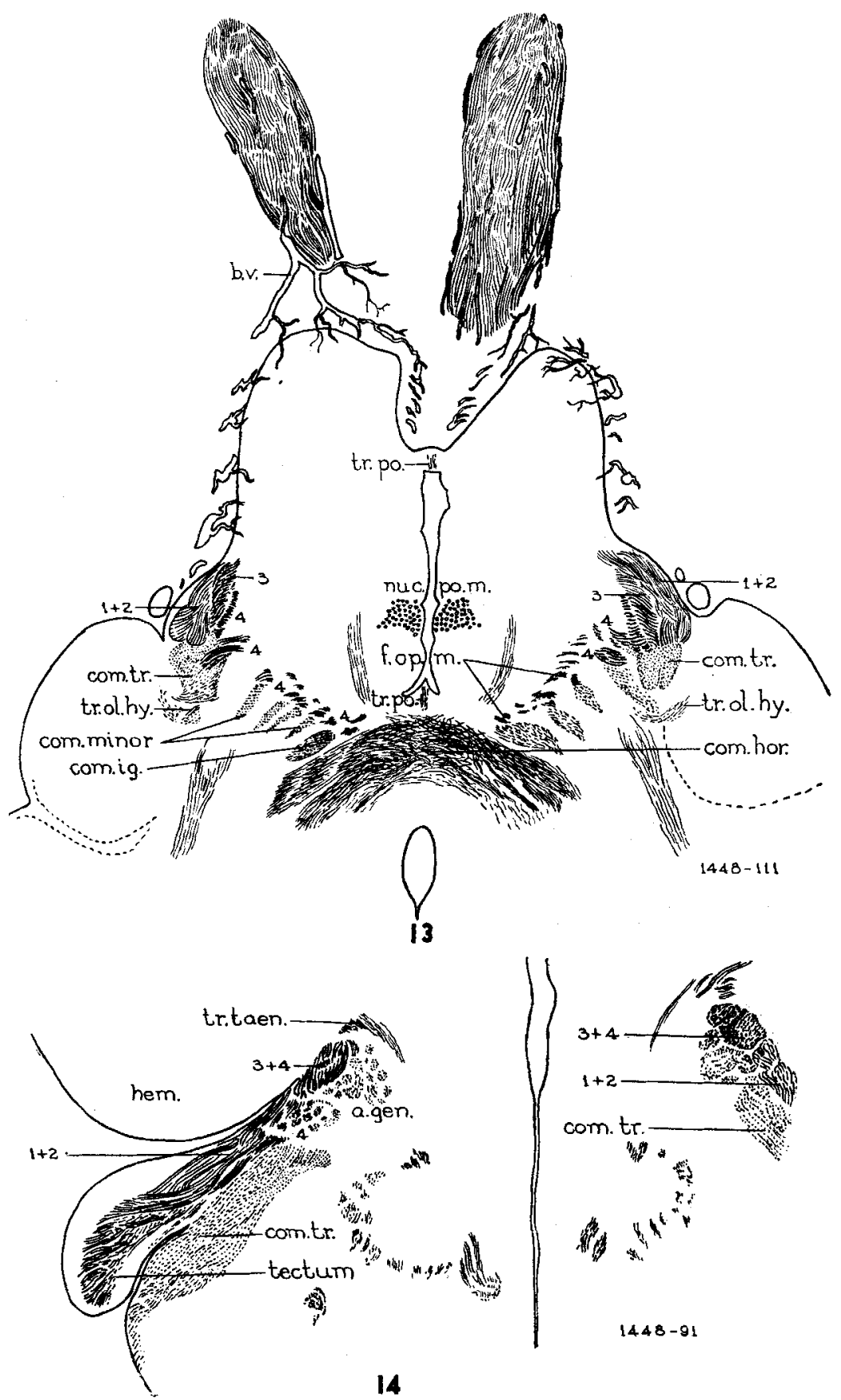

14 
fascicles to join those just mentioned (figs. $8,9,12,13$ ). Some of these and a larger bundle still more dorsally connect with the geniculate area (figs. 9, 10,13), and the most dorsal fibers of this system comprise the commissura minor. The latter accompanies the slender wisps of optic fibers of group 4 which compose the thalamic fasciculus medialis. They are present but not drawn in the section shown in figure 9; compare the horizontal section, figure 13. The figure last mentioned shows also the crossing of the commissura horizontalis. Slender feebly myelinated fibers of the commissura tuberis cross at the posteroventral border of the chiasma ridge (fig. 5).

In the median floor there are two small well defined tracts containing unmyelinated and a few well myelinated fibers which connect with that segment of the nucleus preopticus magnocellularis which occupies the posterodorsal border of the chiasma ridge (fig. 5). Tractus preopticus passes from the posterior border of the anterior commissure ridge into the floor of the preoptic recess, then backward and upward along the anterior face of the chiasma ridge, to disappear among the cells of the nucleus preopticus magnocellularis of the chiasma ridge. This course is clear in sections cut in all three planes. Some of these fibers may pass through the nucleus to enter tractus hypophyseus, but these preparations yield no evidence of this connection.

Tractus hypophyseus passes from the chiasmatic part of nucleus preopticus magnocellularis into the floor of the infundibulum and then into the hypophysis, where its myelinated and unmyelinated fibers ramify widely. This part of the tract is well defined in sections cut in all planes, but the details of its distribution in the hypophysis cannot be determined. As shown in figure 8 , feebly myelinated fibers pass out from the ventrolateral border of each of the two anterior sectors of nucleus preopticus magnocellularis. These descend to the commissura transversa and appear to thread their way among its fascicles and then continue posteroventrally to enter tractus hypophyseus at the posteroventral border of the chiasma ridge (figs. 8 to 12). These few myelinated fibers are pale, scattered 
and mingled with others, so that their identification is difficult, but it is believed that the course indicated (though questioned) on the figures is correct. ${ }^{2}$

\section{Comment}

From personal observation and accounts in the literature it is evident that the teleosts exhibit a great variety of arrangements in the visual apparatus, both peripheral and central. There are several anatomical and physiological components here which may develop at different times in ontogeny and which have different types of central connections. Among the fishes these systems evidently are variously developed, depending on bodily structure and mode of life. Little is known of the details of these matters, but a beginning has been made.

In the attempt to interpret these observations it should be borne in mind that in siluroid fishes the eyes and central visual apparatus are relatively small and that in experiments reported many years ago ('03, pp. 251, 270) I found that $\mathrm{A}$. nebulosus makes little use of the eyes in the ordinary capture of food. In contrast with species with large eyes where visual reactions dominate the behavior, retinal patterns may not be projected upon the cerebral centers so precisely and more generalized visual functions may be relatively far more prominent. The anatomical arrangements suggest that if retinal quadrants are projected upon the tectum, this localization is not sharply defined and that a large proportion of the optic fibers are primarily concerned with other functions.

In Amblystoma I find ('41) in the larvae little anatomical evidence of retinal projection upon the tectum. Very coarse axons arise in all retinal quadrants and enter all fascicles of the optic nerve. At the chiasma most of these largest fibers

\footnotetext{
2 The two divisions of the magnocellular part of the preoptic nucleus which are widely separated in Ameiurus are in Lota lota connected by a cellular strand, as shown in figures by Boon ('38, fig. 4). These figures show clearly that in Lota the tractus hypophyseus arises from both divisions of the nueleus magno. cellularis.
} 
are segregated in the dorsal chiasmatic bundle 4, from which they ascend across the thalamus in the so-called axial bundle of the optic tract, which takes a deeper course than the marginal bundles of the tract and distributes its fibers to both dorsal and ventral tectal tracts, probably more in the former than in the latter. These coarse fibers apparently can perform no sharply defined localizing functions. They appear first in ontogeny and predominate in the very young stages. With advancing age the relative number of finer fibers is increased and their number is multiplied about tenfold at metamorphosis.

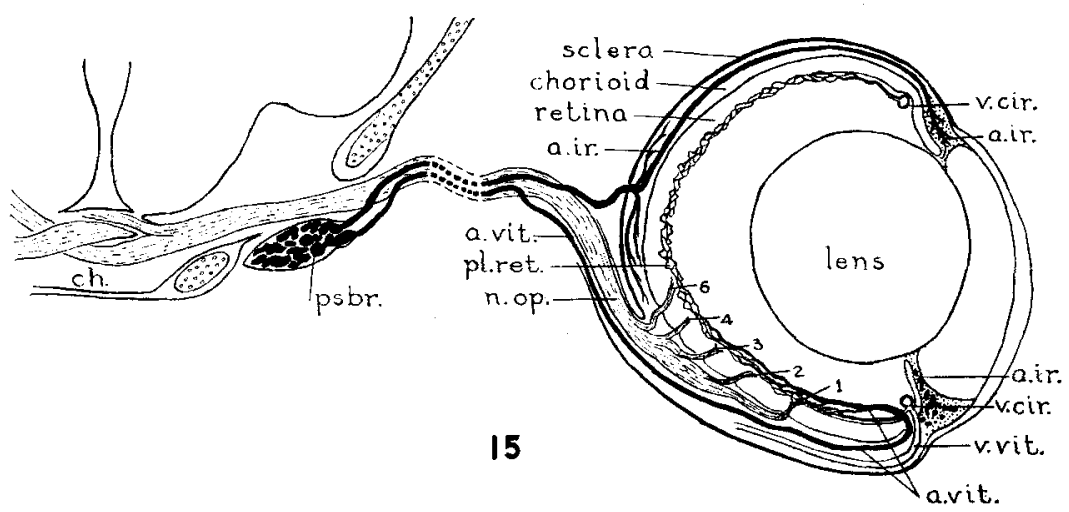

Fig. 15 Diagram (not to scale) of the arterial blood supply of the eyeball of A. melas seen as projected upon a transverse plane. $\times 24$. Broken lines in the middle of the optic nerve indicate the omission of part of the nerve here. At the chiasma the perforation of the right nerve by the left is apparently an individual variation, for it is not present in any of several other specimens.

It is suggested that in Amblystoma the localized projection of retinal quadrants upon the tectum, so far as present in this animal, is mediated by the finer optic fibers and that the coarsest fibers perform other functions. The arrangement in Ameiurus is similar in principle, though the anatomical configuration is very different. In this fish coarse fibers arising in all retinal quadrants are uniformly distributed in all fascicles of the optic nerve and in the chiasma region they tend to accumulate in the dorsomedial bundles of group 4, which are widely separated from the other optic fibers. Some 
of these separated fibers, including those of the fasciculus medialis, terminate in the ill-defined geniculate area of the thalamus ; but the majority of them enter the aberrant fascicles, rejoin the marginal bundles and terminate in the tectum. The origin, course and distribution of the fibers of the aberrant optic fascicles of Ameiurus are so similar to those of the axial fibers of Amphibia as to suggest that they perform similar functions. Further experimental study of the visual functions of these fishes may be fruitful.

In comparing the distribution of the coarse optic fibers of fishes and amphibians with those of mammals caution must be observed, for the thickness of nerve fibers is correlated with their speed of conduction. Different animals with diverse modes of life may employ tracts of fibers which are morphologically homologous very differently, and these physiological differences may be reflected in radical changes in the structure of the nervous conductors employed. Thus, with the transfer in mammals of the dominant control of visual reactions from midbrain to cortex, the time factors in these reactions are profoundly changed and "fast traffic" to the cortical centers may employ thicker fibers than the more generalized functions of the brain-stem. These problems can be resolved only by correlated anatomical and physiological studies, for which fortunately we now have adequate technical methods.

\section{OCULAR BLOOD VESSELS}

I venture to report here some details about the blood vessels of these eyes, even though the material is not suitable for a complete and reliable analysis and though I am in complete agreement with H. Virchow's contention ('01, p. 777) that section pictures are inadequate without three-dimensional representation from injections or reconstructions. These fragmentary observations fortunately can be checked and oriented in the light of Virchow's own brief references to the vascularization of the eyes of Silurus and Ameiurus. He says ('01, p. 778) that in siluroids, unlike some other fishes, there is an unusually rich vascular net bordering the retina. 
In the eel both artery and vein connect with the retina at the optic papilla accompanying the optic nerve fibers, thus at the central end of the closed chorioid fissure. In the cyprinoids the artery enters at the papilla and ramifies in the vascular net at the border between retina and vitreous, from which venules pass to a circular vein surrounding the lens at the ora serrata. The efferent discharge from this circle is by a vein leaving it on its ventral side, thus at the peripheral end of the closed chorioid fissure. In siluroids both artery and vein pass between the chorioid and vitreous chamber at the ventral side of the ora serrata, i.e., at the place where the vein emerges in cyprinoids (Virchow, $1882 \mathrm{a}$, p. 47). The siluroid arrangement has some points of similarity with that of the frog, though the differences are really very fundamental (Virchow, 1881, p. 270; 1882 a, p. 43).

Since I find in the literature no detailed description of these vessels of Ameiurus, my own observations are here reported. In the three specimens of A. melas studied, including four eyes, the intrinsic vessels of the eye are naturally injected with blood. The injection is incomplete, but it differs in the four eyes, so that by assembling data from all of them the arterial supply of the eye is completely seen, as shown in the diagram (fig. 15). The veins are not so well preserved and their description is less complete.

The two intrinsic arteries of the eyeball arise independently from the rete mirabile of the pseudobranch. They are, therefore, not comparable with the central artery of the retina or the vitreous (hyaloid) artery or the iridian arteries of those other teleosts in which these vessels are branches of the ophthalmic artery (Virchow, 1882, pp. 577, 587). They are here named in accordance with their intraocular distribution. One of them I call the iridian artery and the other the vitreous artery, without implying homology with any arteries of other species.

The small pseudobranch lies ventrally of the optic nerve externally of the optic foramen (fig. 15 and '01, fig. 3, psbr.). Two arteries arising from this rete are directed laterally 
parallel with the optic nerve. Neither of these vessels gives obvious branches until after its penetration into the eyeball. There is no central retinal artery or vein. The optic nerve and its connective tissue sheaths are permeated by a plexus of very small vessels which enter the nerve at the optic chiasma (p. 270 and fig. 13) and none of these vessels, so far as observed, accompany the optic nerve fibers to their retinal papillae.

The iridian and vitreous arteries after leaving the pseudobranch follow the posterior border of the optic nerve, well separated from it, between the dense inner and the looser outer connective tissue sheaths of the nerve, the iridian artery being more dorsal. Parallel with them are two large veins which collect blood from the eyeball and discharge backward into the orbital vein (shown at the level of the optic foramen in the paper of 1901, fig. 3, b.v.). The arrangement of these four vessels as seen in cross sections of the optic nerve differs somewhat from that illustrated by Deyl (1895, fig. 2) in A. catus (nebulosus?), but the differences are probably of no special significance.

In our specimens the iridian artery leaves the optic nerve near the eyeball and penetrates the sclera quite far dorsally of the place of exit of the nerve. The vitreous artery follows the ventral border of the nerve and enters the eyeball with it (figs. 4,15 ). The two ocular veins take similar courses, not closely associated with the optic nerve or with the two arteries, and each emerges from the eyeball by a separate opening in the sclera.

The iridian artery immediately after entrance through the sclera gives several branches which ramify widely in the chorioid. The main trunk passes directly laterally in the dorsal chorioid and above the ora serrata it enters the dorsal border of the ciliary body and here breaks up into numerous branches, forming a plexus which encircles the pupil. The details of this plexus and the venous return were not observed.

The vitreous artery, having entered the chorioid, passes direetly laterally without branching. At the most ventral 
point of the ora serrata it turns sharply inward through the retina into the vitreous chamber. Here it turns back parallel with its former course and ramifies over the whole inner face of the retina, still lying in the vitreous chamber. As already pointed out, the main stem of this vitreous artery takes a meridional course from the peripheral to the central end of

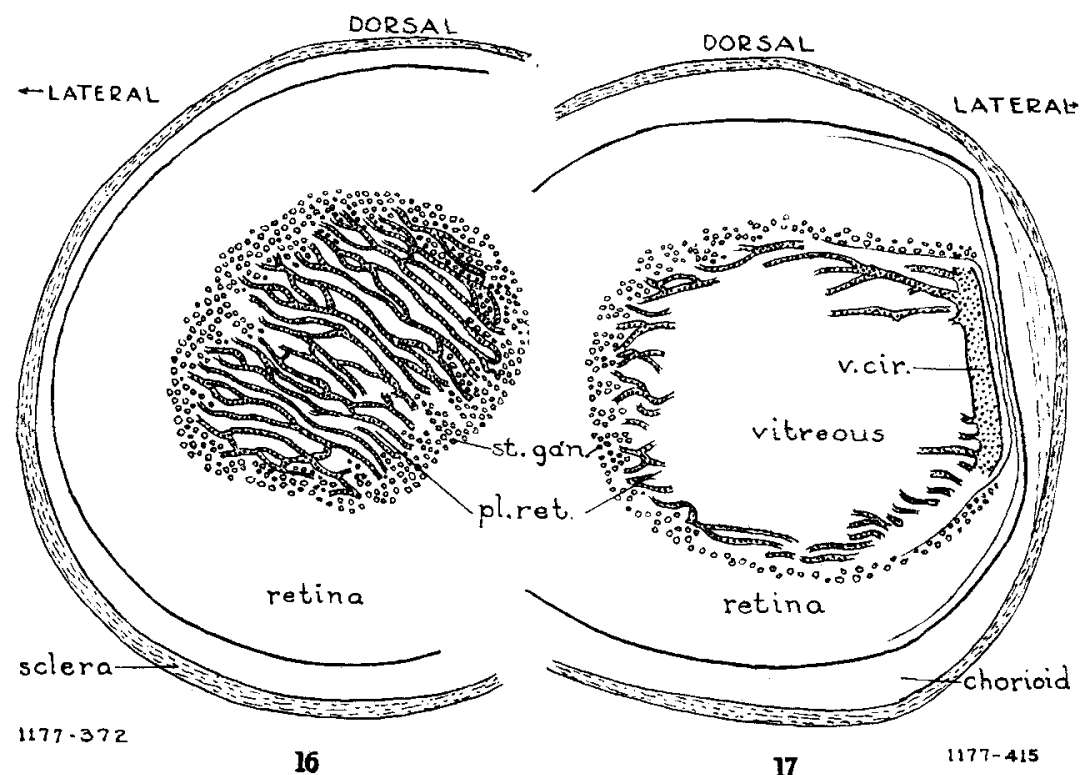

Fig. 16 Transverse section through the posterior border of the vitreous body of the left eye of A. melas, showing a detail of the retinal capillary plexus. $\times 60$.

Fig. 17 A similar section from the right eye of the same specimen taken a short distance farther anteriorly at the posterior are of the circular vein. The venules from the retinal vascular net are entering the circular vessel at the ora serrata. $\times 60$.

the zone which includes the region of the closed chorioid fissure. Within this zone are all of the optic papillae which thus occupy the region of most direct arterial blood supply.

The terminal arterioles of the vitreous artery enter a closemeshed capillary net which is spread over the outer face of the vitreous body, thus covering the inner surface of the retina as far out as the ora serrata. From all parts of this capillary 
net venules pass outward from the central part of the retina toward its periphery in closely seriated formation. These discharge into a circular vein which forms a closed ring at the ora serrata on the inner, or vitreous, side of the ciliary part of the retina. From the ventral side of this circular vein a large efferent vessel (the vitreous vein) passes out of the vitreous chamber through the retina to enter the chorioid, where it turns sharply medially running parallel with the vitreous artery and externally of it. Its farther course cannot be followed in this material. As they pass through the retina at the ora serrata the vitreous artery and the vitreous vein lie very close together and in our natural injections either one may be gorged with blood and the other empty, or both may be filled. The capillary net and the circular vein are well injected.

Figure 17 illustrates a transverse section taken near the posterior border of the right eye, cutting through the posterior are of the circular vein and showing the discharge into it of the venules from the capillary net. These parallel venules enter the circular vein close together, thus forming a radiating crown of vessels around the entire circumference of the vascular ring at the ora serrata. Figure 16 is a similar section from the left eye of the same specimen taken a little more posteriorly and cutting the posterior convexity of the capillary net tangentially. These capillaries, here midway between the central and peripheral parts of the retina, form a plexus with elongated meshes, for they are directed, in general, outward toward the venules which enter the circular vein.

This capillary net is not part of a retinal system of vessels derived from a central retinal artery, like that of mammals and some other fishes (Virchow, 1882). It belongs to the vitreous system of vessels; yet its relations with the retina are very intimate. As shown in figures 16 and 17, capillary loops project outward, occupying grooves in the retinal surface separated by ridges containing ganglion cells and fascicles of nerve fibers. This vascular net, though morphologically 
part of a vitreous system of vessels, is physiologically a retinal system, and it furnishes the only blood supply of this retina. The vitreous artery and vein, moreover, seem to have no connections other than with this retinal net.

The morphological significance of these vessels of Ameiurus and their variants in other fishes and in other classes of vertebrates has been fully discussed by Virchow in the papers cited and by Viktor Franz ('13). The vessel of Ameiurus which I term the vitreous artery is called by Deyl (1895) the hyaloid artery; but this is inappropriate for reasons given by Virchow (1882 a, pp. 41-44), for this artery arises directly from the pseudobranch and has no connection with an ophthalmic artery or the embryonic hyaloid artery derived from the latter.

In view of the peculiar type of nervous control of movements of the visual elements and pigment of the retina of Ameiurus described by Arey ('16) and of related studies by him, Detwiler, Parker and others, further investigation of the vascularization, innervation and endocrines of the teleostean eye is desirable.

\section{SUMMARY}

In very young Ameiurus of $10 \mathrm{~mm}$. there are four distinct retinal papillae, each of which receives optic fibers from a single retinal quadrant. In older fry and adults there are eight to ten papillae whose fibers are not specifically related with retinal quadrants. These lie in a zone which probably marks the place of closure of the embryonic chorioid fissure. In the axis of this zone is a large vitreous artery which supplies the retinal capillary net. Fascicles of fibers from the retinal papillae take separate courses through the retina and within the chorioid they unite to form the trunk of the optic nerve.

The optic nerve of adult A. nebulosus contains from 50 to 100 small fascicles, each of which has many thin and medium myelinated fibers and a few of larger diameter. The latter are derived from all retinal quadrants. These fascicles inter- 
weave and anastomose and there is no evidence that fibers from the several retinal quadrants are segregated.

As the chiasma is approached, most (but not all) of the coarsest fibers assemble at the dorsolateral side of the nerve. After decussation these fascicles are dorsomedial. At the chiasma and proximally of it the optic fibers are obscurely separated in three bundles which are here numbered in accordance with the scheme adopted in my current description of Amblystoma ('41). Chiasmatic fascicles $1+2$, chiefly of finer fibers, are lateral in the optic tract and most of their fibers enter the ventral tectal tract. Bundle 3, with a larger proportion of coarse fibers, is medial in the optic tract and most of its fibers enter the dorsal tectal tract. Bundle 4, chiefly of very coarse fibers, upon entrance into the brain separates from the others and ascends across the anterior face of the postoptic commissure complex in and near the median plane. Its most medial fascicles enter the geniculate area of the thalamus and appear to terminate here. Its more lateral fibers, the aberrant fascicles, turn laterally deeply embedded in the gray of the preoptic nucleus, to rejoin those of bundle 3 in the marginal optic tract. Most of these enter the dorsal tectal tract, some the ventral tract and the geniculate area.

The aberrant fibers of chiasmatic bundle 4 resemble in origin, course and distribution those of the axial optic tract of Amphibia. In both cases they show no evidence of central localization correlated with retinal quadrants, and it is suggested that they probably serve the more generalized visual functions. Projection of retinal quadrants upon the tectum may be effected by other fibers of the visual system, though if so these fibers do not appear to be segregated by retinal quadrants in the peripheral course of the optic nerve.

The blood supply of the siluroid eye is peculiar and some further details of the arrangement of these vessels are contributed. 


\section{LITERATURE CITED}

AREY, LesLie B. 1916 The function of the efferent fibers of the optic nerve of fishes. J. Comp. Neur., vol. 26, pp. 213-245.

Boon, A. A. 1938 Comparative anatomy and physio-pathology of the autonomic hypothalamic centres. Dissertation (Amsterdam). Haarlem, de Erven F. Bohn.

Bruesch, S. R., AND L. B. AREY 1940 An enumeration of myelinated and unmyelinated fibers in the optic nerve of vertebrates. Anat. Rec., vol. 76 (abstract), p. 10.

DEYL, J. 1895 Ueber den Sehnerven bei Siluroiden und Acanthopsiden. Anat. Anz., Bd. 11, S. 8-16.

Franz, Viktor 1912 Beiträge zur Kenntnis des Mittelhirns und Zwisehenhirns der Knochenfische. Folia Neurobiol., Bd. 6, S. 402-441.

1913 Sehorgan. A. Oppel's Lehrbuch der vergleichenden mikroscopischen Anatomie der Wirbeltiere. Teil 7. Jena.

HERRICK, C. JUDSON 1891 Contributions to the morphology of the brain of bony fishes. I. Siluridae. J. Comp. Neur., vol. 1, pp. 211-228. 1901 The cranial nerves and cutaneous sense organs of the North American siluroid fishes. J. Comp. Neur., vol, 11, pp. 177-249.

1903 The organ and sense of taste in fishes. U. S. Fish Commission Bulletin for 1902, pp. 237-272.

1941 Development of the optic nerves of Amblystoma. J. Comp. Neur., vol. 74 , pp. $473-534$.

1941 a Optic and postoptic systems of fibers in the brain of Necturus. J. Comp. Neur. (In press.)

Herrick, C. L. 1892 Studies on the brain of some American freshwater fishes. J. Comp. Neur., vol. 2, pp. 21-72.

Meader, R. G. 1934 The optic system of the teleost, Holocentrus. J. Comp. Neur., vol. $60, \mathrm{pp}, 361-407$.

Mrller, RUTh N. 1940 The diencephalic cell masses of the teleost, Corydora paliatus. J. Comp. Neur., vol. 73, pp. 345-378.

PARKER, G. H. 1903 The optic chiasma in teleosts and its bearing on the asymmetry of the Heterosomata (flat fishes). Bul. Mus. Comp. Zool., vol. 40 , pp. $222-242$.

STRöER, W. F. H. 1939 Zur vergleichenden Anatomie des primären optischen Systems bei Wirbeltieren. Zeits. f. Anat. u. Entw., Bd. 110, S. 301-321.

Verrier, Marie-Louise 1928 Recherches zur les yeux et la vision des poissons. Bul. Biol. de France et de Belgique, supplement no. XI, Paris.

VIRchow, H. 1881 Ueber die Gefässe im Auge und in der Umgebung des Auges beim Frosche. Zeits. f. wiss. Zool., Bd. 35, S. 247-281.

1882 Ueber die Glaskörper- und Netzhautgefässe des Aales. Morph. Jahrb., Bd. 7, S. 573-590.

1882 a Beiträge zur vergleichenden Anatomie des Auges. Habilitationsschrift. Berlin.

1901 Fächer, Zapfen, Leiste, Polster, Gefässe im Glaskörperraum von Wirbeltieren sowie damit in Verbindung stehende Fragen. Merkel u. Bonnet's Ergebnisse, Bd. 10, S. 720-844. 